\title{
Energiesparendes Haus der Zukunft
}

Die Energieeffizienz hat einen zunehmenden Stellenwert, um einerseits die Abhängigkeit von fossilen Ressourcen und den damit verbundenen Emissionen zu begrenzen und andererseits, um die Energiekosten zu verringern.

Hierzu laufen derzeit Projekte im Bereich der Energieumwandlung, der Nutzung der Endenergie, im Verkehrsbereich und bei den Großgebäuden.

Dieses Heft beschäftigt sich mit dem energiesparenden Haus der Zukunft.

Im Bereich der Großgebäude finden wir heute komplexe Infrastruktursysteme, die durch Gebäudeautomatisierungssysteme überwacht, gesteuert und geregelt sowie hinsichtlich ihrer Energieeffizienz optimiert werden. Dieses Themengebiet soll hier interdisziplinär beleuchtet werden.

Die Basis für die Gebäudeeffizienz bildet energiesparendes Bauen, das bei Neubauten leicht zu verwirklichen ist. Bei Altbauten sind wegen der hohen Kosten Grenzen für die Sanierung gesetzt.

Niedriger Energiebedarf ist die Voraussetzung für Passivhäuser, die überwiegend solare Energie für den Heizungsbedarf, die Warmwasserbereitung und neuerdings auch für die Gebäudeklimatisierung verwenden.

Dezentrale Erzeugungssysteme mit Brennstoffzellen oder Mikroturbinen lassen sich für die Strom- und Wärmeversorgung einsetzen. Ihre eigentliche Bedeutung werden sie erhalten, wenn es gelingt, sie bei Versorgungsunterbrechungen zu autonomen und damit sicheren Energiesystemen zu erweitern. Hierzu sind noch einige Arbeiten zu leisten, im Bereich der Verbrauchsanalyse, des Demand Side Managements, der autonomen Betriebsführung dezentraler Energiesysteme im netzstörungsbedingten Inselbetrieb und des bedarfsgerechten Erzeugungsmanagements.

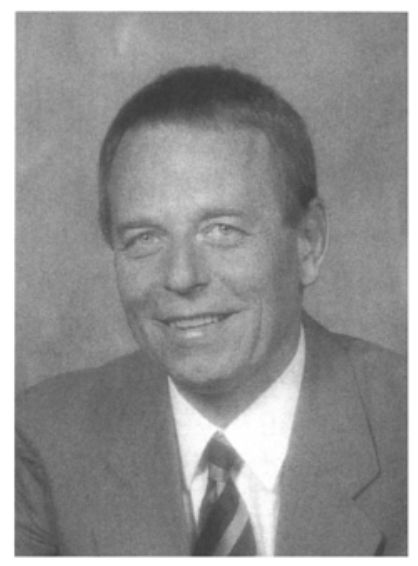

Die Gebäude sind hierfür besonders interessante Objekte, da hier hoher Energiebedarf mit hohem Sicherheitsbedürfnis zusammenkommt und weiterhin die Infrastruktursysteme für die spezifischen Aufgaben jeweils neu aufgebaut werden können.

Bessere Energienutzung und gleichzeitig hohe Versorgungssicherheit werden für die Gebäude ein wichtiges Thema.

Wie die Beiträge zeigen, laufen intensive interdisziplinären Forschungen auf diesem Gebiet.

Ihr

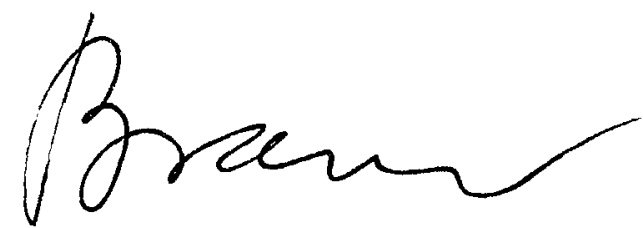

Günther Brauner 